\title{
Monitoring the influence of marine aquaculture on wild fish communities: benefits and limitations of fatty acid profiles
}

\author{
Damian Fernandez-Jover ${ }^{1, *}$, Pablo Arechavala-Lopez ${ }^{1}$, Laura Martinez-Rubio ${ }^{2}$, \\ Douglas R. Tocher ${ }^{2}$, Just T. Bayle-Sempere ${ }^{1}$, Jose Angel Lopez-Jimenez ${ }^{3}$, \\ Francisco Javier Martinez-Lopez ${ }^{3}$, Pablo Sanchez-Jerez ${ }^{1}$ \\ ${ }^{1}$ Department of Marine Sciences and Applied Biology, University of Alicante, PO Box 99, 03080 Alicante, Spain \\ ${ }^{2}$ Institute of Aquaculture, University of Stirling, Stirling FK9 4LA, UK \\ ${ }^{3}$ Department of Physiology, Faculty of Biology, University of Murcia, Campus of Espinardo, 30100 Murcia, Spain
}

\begin{abstract}
Fatty acids (FA) have been applied as indicators of the influence of coastal sea-cage fish farming on wild fish communities in several recent scientific publications. Due to the relatively high conservation of FA composition throughout the food web, they are useful for characterizing trophic relationships. The increasing utilization of vegetable or alternative animal oils in the production of aquafeeds results in cultivated fish exhibiting higher levels of terrestrial FAs in their tissues. As previously reported, wild fish ubiquitously aggregate around fish farms as a consequence of the introduction of new habitat and the easy availability of food-fish farms act as enhanced fish aggregation devices (FADs). The influence of food pellets on the composition of wild fish has been detected in recent studies on salmon, sea bass and sea bream aquaculture, with increased levels of linoleic acid (18:2n-6) and a low $n-3 / n-6$ ratio as clear indicators of the consumption of food pellets from the farms. The potential ecological and physiological effects on wild fish are presently unknown. In the present article, guidelines are proposed for the investigation and use of terrestrial FAs to track the effects of coastal aquaculture on wild fish communities and local fisheries, as well as the benefits or limitations of this technique.
\end{abstract}

KEY WORDS: Fish farms - Impact · FADs · Trophic marker · Biomarker · Vegetable oils · Marine resources $\cdot$ Management $\cdot$ Fish assemblages

\section{INTRODUCTION: USE OF FORMULATED FEED WITH INCREASING TERRESTRIAL VEGETABLE INGREDIENTS}

Most farmed marine fish are carnivorous species such as Atlantic salmon Salmo salar, gilthead seabream Sparus aurata, European sea bass Dicentrarchus labrax and Japanese amberjack Seriola quinqueradiata, among others, that require marine ingredients in their feed in order to achieve an optimal growth rate and health status. However, there are many reasons why the aquaculture industry has been researching alternatives to fishmeal (FM) and fish oil (FO), since these products are both increasingly difficult to obtain and their costs have increased considerably. One of the main reasons is the status of traditional fisheries. Captures of wild fish have remained stable since the 1980s despite technical improvements, indicating that fish stocks are being exploited at their maximum levels (FAO 2009). Although improvements to feed-grade fisheries exploitation have been made (Welch et al. 2010), it appears that such fisheries still need to realise important progress in terms of correct labelling-regarding 
both captured species and their origins - which may compromise the sustainability of this marine resource (Deutsch et al. 2007). In addition, due to increasing demand, not only by the aquaculture industry, but also by terrestrial animal farming, the prices of feedgrade marine fishery resources have risen; FM increased in price from US $\$ 694$ to US $\$ 1379 \mathrm{t}^{-1}$ between 2005 and 2006, and FO prices rose from US \$894 to US \$1700 between 2007 and 2008 (Tacon \& Metian 2008). Industry access to feed-grade fisheries may be decreased due to global warming and world agreements to reduce poverty and to increase food security and sustainability, along with ethical issues (De Silva et al. 2010). As a consequence, the aquaculture industry may prefer to rely on more stable and reliable land-based plant production rather than the highly fluctuating marine resources.

This scenario has driven research for alternatives to FM and FO in formulating aquaculture feeds. Much research has focussed on determining the optimal proportions for the substitution of FM and FO by plant products, without compromising fish growth and health status (Turchini et al. 2009, 2010). However, vegetable oils (VO), like soybean, rapeseed, linseed, or palm oils are rich in saturated acids like palmitic (16:0) or stearic acid (18:0), monounsaturated fatty acids like oleic acid (18:1n-9), and polyunsaturated fatty acids (PUFA), especially linoleic acid (18:2n-6) and $\alpha$-linolenic acid (18:3n-3), but lack the long-chain PUFAs (LC-PUFA) eicosapentaenoic acid (20:5n-3, EPA) and docosahexaenoic acid (22:6n-3, DHA) characteristic of FO (e.g. Turchini et al. 2010). Other alternative lipid sources are also being investigated, including terrestrial animal fats or alternative marine oils (e.g. zooplankton), but these resources also have limitations, having only very low levels of n-3 LC-PUFA or by having very limited and insufficient production, respectively, to satisfy current industry requirements (Bureau \& Meeker 2010, Olsen et al. 2010). Despite the lack of n-3 LC-PUFA, VO have been the replacement of choice for FO due to considerations of availability and sustainability, and so considerable research efforts and investments have been applied in this field. Consequently, significant advances in the substitution of fish products by plant proteins and VO have been achieved (Turchini et al. 2009, 2010).

The replacement of FO with alternative oils such as $\mathrm{VO}$ in aquafeeds can cause alterations in fish physiology, including the immunological status of cultivated fish. These effects have been extensively studied and can be controlled under laboratory or cage conditions in order to achieve the maximum levels of substitution without compromising fish performance (Turchini et al. 2009, 2010, Montero \& Izquierdo 2010). However, the use of alternative ingredients in aquaculture is prompting further questions about their effects on the environment. Several studies have appeared highlighting that the FA composition of sediments (Colombo et al. 1997), wild fish populations (Skog et al. 2003, Fernandez-Jover et al. 2007, 2009, 2011) and other associated fauna-like shrimps (Olsen et al. 2009) can be altered as a consequence of food pellets that are not consumed by the cultured fish and are lost from the cages. Therefore, terrestrial FAs have been proposed as biomarkers for the influence and impact of aquaculture on wild fish populations (Skog et al. 2003, Fernandez-Jover et al. 2007).

Wild fish aggregations around coastal sea-cage farms may reach high numbers and biomass (Dempster et al. 2002, 2009), and changes in the FA profile of this fauna have been detected in both adult and juvenile fish (Skog et al. 2003, Fernandez-Jover et al. 2007, 2009). This work presents the current status and knowledge of the effects of FAs of terrestrial origin on wild fish communities, focusing on future research efforts and monitoring guidelines for using FAs as biomarkers and also considering the potential effects on fish biology.

\section{EFFECTS OF LOST FOOD PELLETS ON WILD FISH FA SIGNATURE}

Fish are attracted towards floating objects, both moored and drifted. These objects, which may be natural (like logs, floating seaweed, jellyfish etc.) or artificial (docks, jetties, oil platforms, fishing gears etc.), are known as fish aggregation devices (FADs) and have been traditionally used as methods for enhancing fisheries captures (Kojima 1956, Fonteneau et al. 2000, Dempster 2004). Fish farms also act as FADs (Carss 1990, Bjordal \& Skar 1992, Dempster et al. 2002). Large numbers of species, estimated to be $>160$ worldwide (Sanchez-Jerez et al. 2011), have been recorded aggregating around floating cages of different farmed fish species, including, among others, salmon, sea bass, sea bream, bluefin tuna and groupers. However, far from acting as traditional FADs, coastal cages function as enhanced aggregating devices principally due to the availability of food in the form of lost food pellets that are not consumed by the farmed fish (Dempster et al. 2002, Tuya et al. 2006).

Most of these aggregated wild fish actively consume the lost particulate organic matter (POM), principally in the form of uneaten food pellets and faeces that fall 
from the cages. For most of the studied aggregating species, it has been demonstrated that they change their diet while resident around farms (FernandezJover et al. 2007, 2008, Dempster et al. 2009) and help to reduce the impact on the benthic system. Thus, wild fish feeding around fish farms reduce the total waste that reaches the environment by 40 to $80 \%$ (Vita et al. 2004, Felsing et al. 2005). Consequently, as wild fish substitute their natural diet by an elevated proportion of food pellets, it was hypothesised that they may present alterations in their FA profiles in a similar way as happens to cultured species.
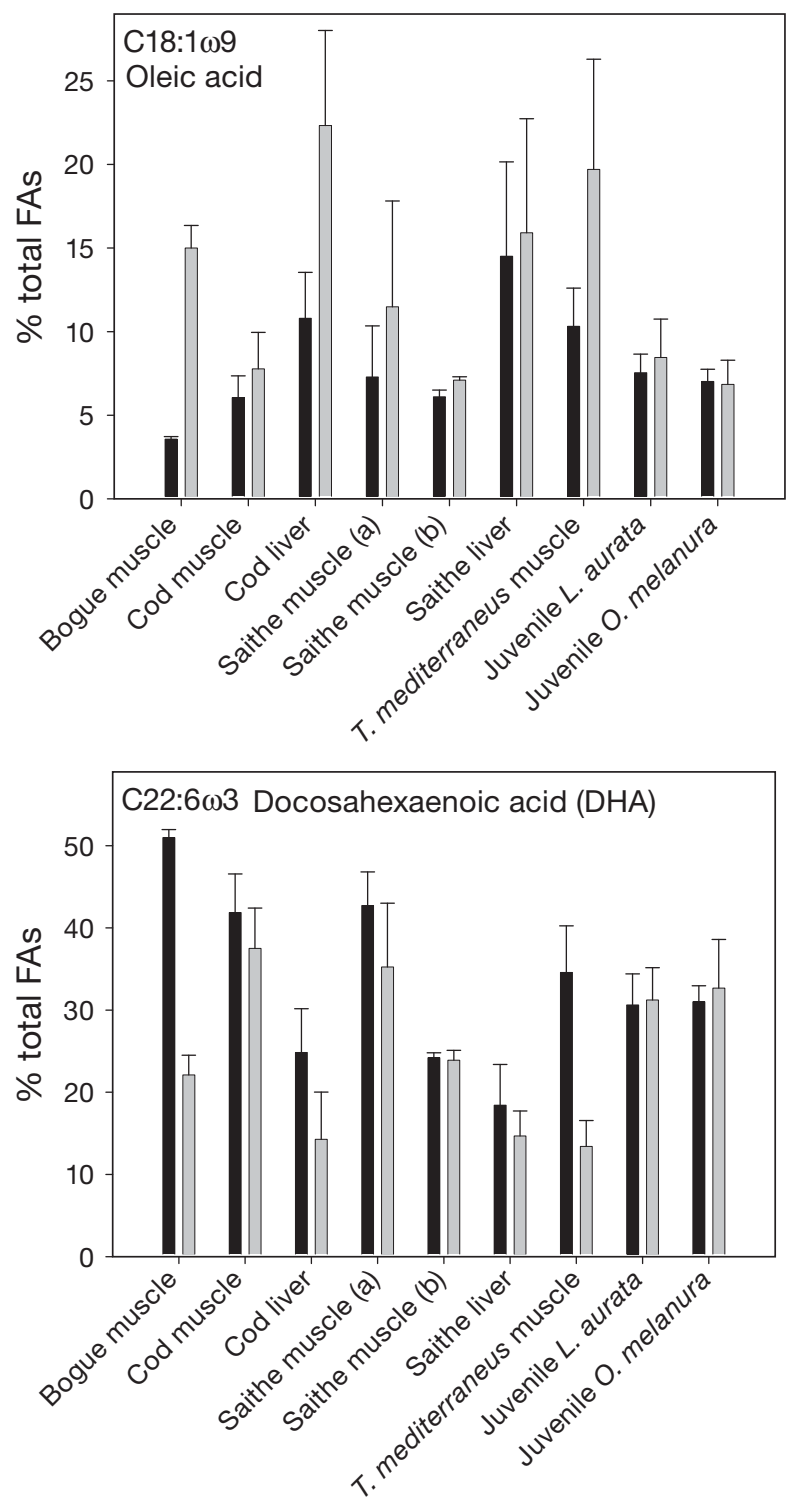

\section{FA profiles of adult fish}

Initially, Skog et al. (2003) found that wild saithe Pollachius virens feeding around a salmon farm in a Norwegian fjord had FA profiles similar to the food pellets used at the farm; with increased levels of linoleic and $\alpha$-linolenic acids as well as a comparatively low n-3/n-6 PUFA ratio (Fig. 1). Norwegian fishermen have traditionally argued that salmon farms affect the behaviour and taste of wild saithe (Carss 1990), and controversy still exists (e.g. Skog et al. 2003, Dempster et al. 2011).
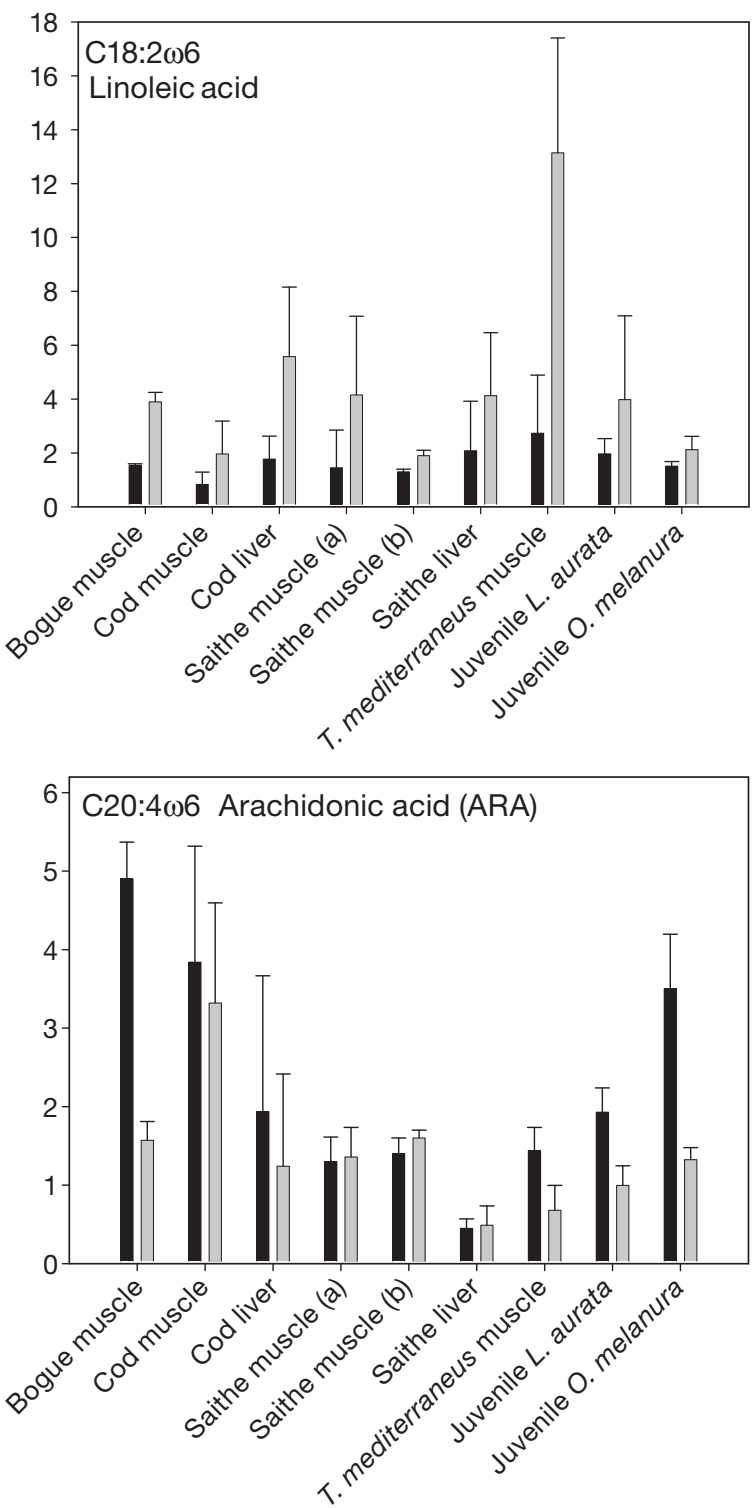

Fig. 1. Literature review of fatty acid (FA) profiles (as percentage of total FAs) of different fish species. Means ( \pm SE) of nonassociated control fish (black bars) and farm-associated wild fish (grey bars). Sources are: Arechavala-Lopez et al. (2010a) for bogue Boops boops; Fernandez-Jover et al. (2011) for cod Gadus morhua muscle, cod liver, saithe Pollachius virens muscle (designated Type a) and saithe liver; Skog et al. (2003) for saithe muscle (designated Type b); Fernandez-Jover et al. (2007) for Trachurus mediterraneus muscle; Fernandez-Jover et al. (2009) for juveniles of Liza aurata and Oblada melanura. Data from Fernandez-Jover et al. (2011) are pooled from 2 different localities. Data from Skog et al. (2003) consider as control fish the wild saithe from a fjord with no farming activity 

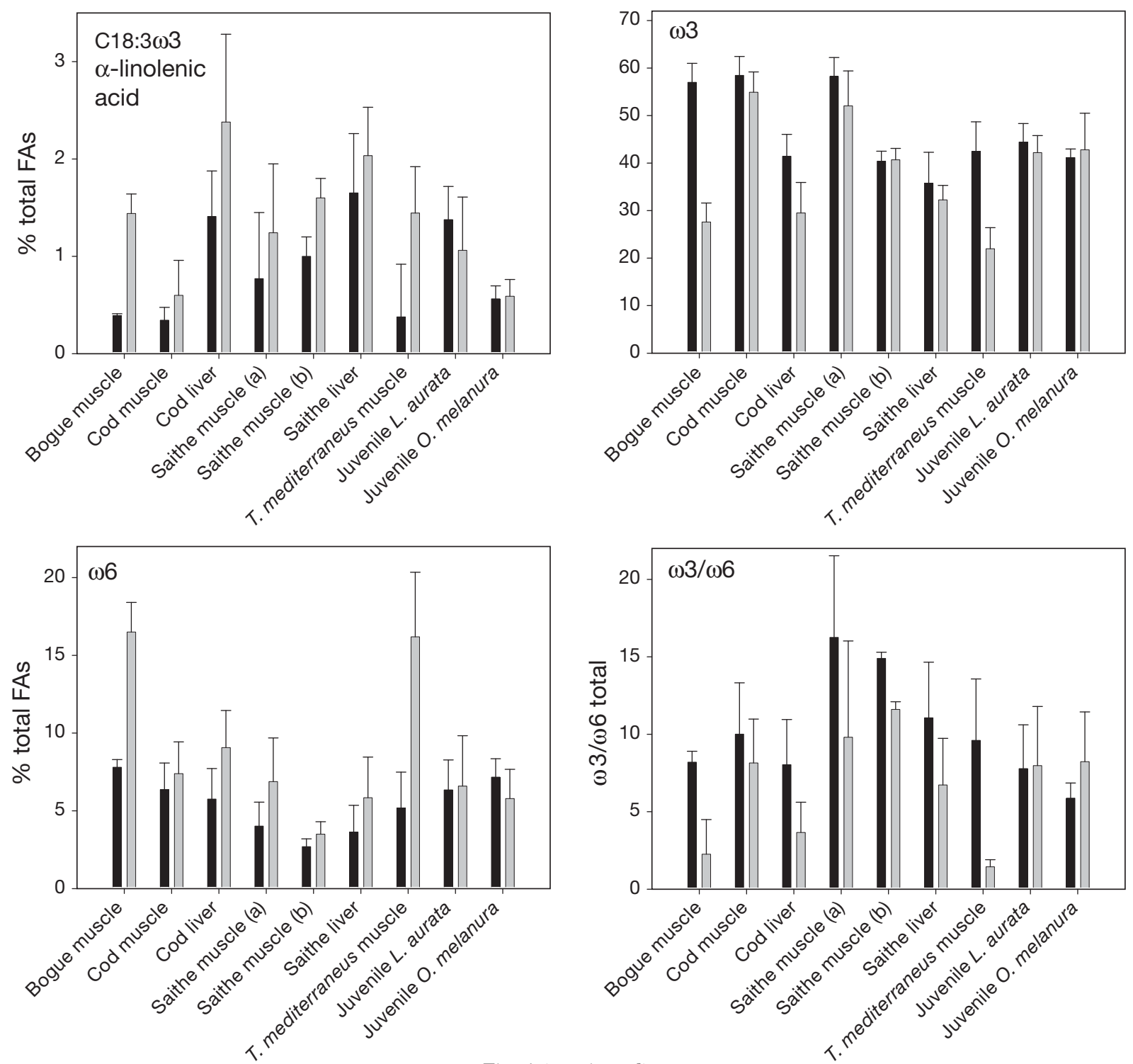

Fig. 1 (continued)

Along with saithe, the FA profiles of cod Gadus morhua around fish farms in Norway have also been studied (Fernandez-Jover et al. 2011). The present study supports the results by Skog et al. (2003) that higher levels of linoleic acid (Fig. 1) are found in farm-aggregated individuals of both species; therefore, this FA appears to be a strong indicator of food pellets in the diet. The present study also analyzed the profiles of livers of associated cod and saithe, showing that the influence of VO was more marked in this tissue than in fish muscle. In this way, significant differences were found for oleic acid due to higher levels in farm-associated cod and significantly decreased levels of DHA (22:6n-3), total LC-PUFA (PUFA with chain lengths of 20 or more carbons) and the n-3/n-6 PUFA ratio. In the case of saithe, in addition to increased levels of linoleic acid in the muscle and liver of aggregated fish, a lower $n-3 / n-6$ PUFA ratio was also detected. In addition, the total amount of n-6 PUFA was significantly higher in farmassociated fish. These results were consistent between 2 localities along the Norwegian coast.

Similarly, Fernandez-Jover et al. (2007) highlighted that farm-aggregated Mediterranean horse mackerel Trachurus mediterraneus drastically changed their feeding behaviour while resident around farms, since food pellets averaged $90 \%$ of total stomach contents while their non-aggregated counterparts mainly consumed juvenile fish, crustaceans and cephalopods. This was clearly reflected in the FA profile of the fish muscle, which showed significantly increased levels of linoleic and oleic acids and decreased DHA in 
farm-associated fish (Fig. 1). Similar results were obtained with Mediterranean bogue Boops boops; muscle samples taken from individuals of this species captured closely associated or near farms presented higher percentages of linoleic, $\alpha$-linolenic, oleic and palmitoleic $(16: 1 n-7)$ acids than samples taken many kilometres from the nearest farm. In contrast, values of DHA, arachidonic acid ( $\left.\mathrm{ARA}_{;} 20: 4 \mathrm{n}-6\right)$ and the n-3/n-6 PUFA ratio were lower in fish sampled near fish farms (Arechavala-Lopez et al. 2010a). Similar changes have also been found in the liver, gill, gonad, adipose tissue and brain of B. boops (L. MartinezRubio unpubl. data). Due to the key role of brain in the regulation of physiological functions, its chemical composition is relatively constant and more resistant to the influence of external factors than other organs (Odutuga 1977). Therefore, modifications found in the brain highlight the importance of this dietary change, proving that the presence of aquafeed in the diet occurs regularly, and the magnitude of this change opens the question as to what may be the extent of the effect on fish health and performance.

\section{FA profiles of juvenile fish}

The role of coastal sea-cage fish farms as habitat for the settlement of fish in early developmental stages or juveniles and its influence on their FA composition in the Mediterranean has also been described. The FA profile of farm-associated juvenile fish is, as happens with adult fish, perceptibly altered (Fernandez-Jover et al. 2009). Again, high levels of linoleic acid and, in this particular case, decreased levels of ARA are the main changes in the FA profiles of the juvenile mugilid Liza aurata and the juvenile sparid Oblada melanura, 2 common species in the Mediterranean that usually settle on shallow rocky shores or seagrass meadows. The staple diet of juvenile fish, zooplankton, also showed a modified FA profile. Therefore, it is still not completely clear if the altered FA signature of juvenile fish is a consequence of them feeding on zooplankton, or the direct consumption of fine particulate food pellets, or both.

Currently, the potential consequences of altered FA composition on the development, health status and reproduction of aggregated adult and juvenile fish species remain unknown. On the one hand, these species are consuming a high-energy diet, providing higher lipid and energetic reserves that could be used, for instance, for the development of the gonads. As evidence of this, aggregated individuals usually present a higher corporal condition index than their not-aggregated counterparts (Skog et al. 2003, Fernandez-Jover et al. 2007, Dempster et al. 2009, 2011). However, the biologically active FA for fish are the LC-PUFA, DHA (22:6n-3), EPA (20:5n-3) and ARA (20:4n-6), and marine fish cannot endogenously synthesize these LC-PUFA from the short-chain PUFAs $\alpha$-linolenic (18:3n-3) and linoleic (18:2n-6) acid and so they require LC-PUFA for optimal growth, health status, reproductive behaviour and successful larval development (Tocher 2010). It has been estimated that, in the SW Mediterranean, at least 20 different fish species settle near coastal farms (FernandezJover et al. 2009), and LC-PUFAs may be a key factor in obtaining high fecundity, egg quality, fertilization and hatching success (Pavlov et al. 2004). Spawners of cultured species are fed a diet differing from that of fish reared for human consumption, namely, one optimizing the requirements for reproduction in terms of gonad development, egg quality and larval survival. According to Van Der Kraak et al. (1998), ARA and other PUFAs are important regulators of steroid biosynthesis in fish. Clear indications of the importance of n-3 LC-PUFAs in larval development have been shown (Brown \& Hart 2010), and eggs are generally considered to be of better quality if they present a higher content of total n-3 LC-PUFA, including enhanced levels of both DHA and EPA (Brooks et al. 1997). Wild fauna that aggregate around farms are mainly adult fish of spawning size (Dempster et al. 2002), and their dietary requirements for optimal reproduction have never been studied. Changes in the FA profile of wild fish may have unknown effects on spawning, egg quality, or larval survival.

\section{FATTY ACIDS AS TROPHIC MARKERS OF AQUACULTURE INFLUENCE ON WILD FISH COMMUNITIES}

Fatty acids have often been used as dietary markers (Iverson et al. 2004). A trophic marker is a compound whose origin can be easily and unequivocally identified, that is inert and does not harm the organisms, is metabolically stable and not selectively processed, and transfers from one trophic level to the next in both a quantitative and qualitative manner (Dalsgaard et al. 2003). Although FAs are not inert compounds, they accumulate over time and represent an integration of dietary intake over days, weeks, or months, depending on the organism and its energy intake and storage rates (Iverson 2009). Many studies have inferred food web relationships from FA 
profiles with clear results (e.g. Graeve et al. 1994, Scott et al. 1999). Therefore, FAs have also been proposed as markers of aquaculture influence due to the change of the FA composition of associated fauna like sea-urchins (Cook et al. 2000, Barberá et al. 2011), mussels (Gao et al. 2006), shrimps (Olsen et al. 2009), fish (Skog et al. 2003, Fernandez-Jover et al. 2007) and also in sediment (Samuelsen et al. 1988, Henderson et al. 1997). Olsen et al. (2009) considered that only linoleic and $\alpha$-linolenic acids can be used as clear aquafeed markers in shrimp Pandalus borealis.

Furthermore, wild fish with FA profiles modified by aquafeeds form an important component of the catch of artisanal fisheries in the SW Mediterranean, reaching local markets, as evidenced by ArechavalaLopez et al. (2010a). Artisanal fishers increase their fishing effort around aquaculture cages where wild fish aggregate and therefore are vulnerable to capture (Akyol \& Ertosluk 2010). Wild bogue aggregated at fish farms and those that were not aggregated but were captured within the same bay with trammelnets presented modified FA profiles. The FA composition of individuals captured by artisanal fishing gears were always more similar to farm-aggregated than to control samples. To improve the capacity for differentiating fish origin, FA profiles can be used along with other techniques, like body morphology (Fleming et al. 1994, Grigorakis et al. 2002), condition indexes (Fernandez-Jover et al. 2007), trace elements (Yildiz 2008, Adey et al. 2009, Percin et al. 2011), stable isotopes (Serrano et al. 2007, Kharlamenko et al. 2008), or genetic methods (Danielsdottir et al. 1997). Fatty acid signature, however, presents advantages with respect to other techniques, since it can give a picture of the impact of farming on the environment as well as nutritional information (such as fat content or the n-3/n-6 ratio) that can aid in the correct labelling of fish products (Standal et al. 2007, Jacquet et al. 2010).

The amount of linoleic acid or the n-3/n-6 PUFA ratio may provide strong signals for measuring the influence of fish farming on local fish communities. However, no single or small pool of FAs exists which can be labelled exclusively as having been derived from food pellets. For instance, linoleic acid is also found in natural marine food, although at low levels. Therefore, several studies have applied a multivariate approach to improve the power of the analysis to discriminate the origin of fish or the impact of $\mathrm{VO}$ on wild fish. Thus, Standal et al. (2007) applied linear discriminant analysis (LDA) based on the scores of a previous principal component analysis (PCA) of liver oils to differentiate between reared and wild cod.
Results revealed that LDA correctly grouped cod liver oils depending on their wild or cultured origin (97 to $100 \%$ of individuals correctly grouped). Similarly, Fernandez-Jover et al. (2011) applied LDA analysis to differentiate between cod and saithe depending on their farm-aggregated or non-aggregated origin. The analysis correctly classified 88.5 and $96.7 \%$, respectively, of cod muscle and liver samples. In the case of saithe, the analysis correctly differentiated $85.7 \%$ of saithe muscle and $96.7 \%$ of saithe liver. Non-correctly classified fish tissues may be due to new arrivals, variation of the different tissues reflecting the diet, natural variability that decreases statistical power, or even technique limitations.

Based on published studies, a range of other different multivariate techniques can be applied to discriminate fish individuals according to their origin, including multidimensional scaling (MDS; Fernandez-Jover et al. 2007), PCA (Skog et al. 2003, Fernandez-Jover et al. 2011), multivariate analysis of variance (MANOVA; Fernandez-Jover et al. 2007, 2009), or analysis of similarity (ANOSIM; Hughes et al. 2005). Nonetheless, a univariate technique may initially be used in order to detect which individual FAs may act as 'key FAs' to discriminate between different fish and to avoid 'noise FAs' that do not aid in discrimination. Moreover, FA signature analysis can be combined with other techniques, such as stable isotope analysis, in order to improve the capacity for detecting fish farm influence and differentiating between fish origins, as has already been applied in other fields (Cook et al. 2004, Kharlamenko et al. 2008). However, despite clear field results in the FA profiles of wild fish previously consuming food pellets, several doubts need to be resolved before specific guidelines can be given for using FAs as trophic markers in fish.

\section{PRESENT KNOWLEDGE GAPS}

Further research using controlled experiments in the laboratory is necessary in order to better assess the incorporation rates of these FAs in different species. The retention time of these FAs in fish tissues must also be analyzed if FAs are to be considered as potential biomarkers for the influence of fish farms on juvenile fish. A key issue is to quantify the minimum residence time of wild fish around the cages and, therefore, the minimum period and quantity of consumption of food pellets that enables detection of significant changes in the FA composition of fish tissues. Aggregated fish undertake seasonal migra- 
tions; thus, many species are not resident around the farms throughout the year (Valle et al. 2007, Fernandez-Jover et al. 2008). It has been estimated that 3 to 4 mo are sufficient time to provoke a substantial change in the FA composition of Mediterranean horse mackerel, which was reflected in a strong increment of linoleic and diminished levels of DHA and the n-3/n-6 PUFA ratio (Fernandez-Jover et al. 2007). It is also known that wild cod and saithe may move among different fish farms within the same area, as has been studied in Norway (Uglem et al. 2008,2009 ) and the Mediterranean with mugilids (Arechavala-Lopez et al. 2010b), thus increasing the duration of food pellet consumption. All of these variables have to be taken into account along with the seasonal and spatial variation in FAs (FernandezJover et al. 2007, Tzikas et al. 2007) in order to clearly identify fish farm influence.

The biology and metabolism of lipids for each species considered may also be a source of variation, since mobilization of different FAs may differ depending on fish species and tissue. For instance, the lipid content of the muscle of gadoids is very low, around $0.5 \%$, with phospholipids representing the major lipid class (Dos Santos et al. 1993, Jobling et al. 2008). Thus, a predominantly structural role of the FA composition is indicated in this tissue, which generally presents a more conservative profile than other tissues like liver. Gadoid liver has a high lipid content consisting of triacylglycerols, with an energetic role, in which FA oxidation is a more dynamic process (Falch et al. 2006). Therefore, fish muscle may provide a clearer record of fish diet during a longer period of time. The generally accepted idea is that the FA composition of fish tissues reflects, in a highly conservative form, the FA profile of the diet. However, some fish have the capacity, to a certain extent, of metabolizing some important FAs. Nonetheless, marine fish are well supplied with biologically active FAs in their natural diet and de novo biosynthesis of LC-PUFA, as mentioned before, is likely to be suppressed in marine carnivores (Tocher 2003) and some herbivores, like Liza aurata (Mourente \& Tocher 1993, Sargent et al. 2002), which is an important species in wild fish aggregations around Mediterranean farms (Fernandez-Jover et al. 2008).

\section{CONCLUSIONS AND GUIDELINES}

Strong evidence exists that FA signatures are modified in fish tissues when they aggregate around sea cages. The most suitable substances for detecting this influence appear to be increased levels of linoleic acid along with decreased levels of DHA and the n-3/n-6 PUFA ratio. A multivariate approach should also be applied in order to obtain powerful and conclusive results when using FAs as biomarkers. It is also necessary to obtain detailed information on the 'natural' FA profiles of the analyzed species of wild fish, as well as the spatial and temporal variability of their lipid composition. Parallel to the development of aquafeeds with alternative ingredients, research is also needed on the effects of food pellets on wild communities in terms of health status or reproductive potential. This gap in our knowledge regarding the effects on fish performance dictates great caution in this case and adds further urgency to the optimization of the usage of food pellets in order to reduce organic wastes and to the usage of avoid economical losses and negative effects on water quality, benthos and associated communities. The increased use of alternative oils in formulated diets poses new questions, since it is possible that, while solving one problem, new problems are being created. However, efforts to improve the efficiency of aquafeeds rich in $\mathrm{VO}$ are increasing, and studies on new species focus mainly on carnivorous fish. In conclusion, it is crucial to increase our knowledge on the degree of impact provoked by the FA composition of aquafeeds on the overall ecosystem.

Acknowledgements. This review forms part of the FATFISH project (Dept. of Marine Sciences and Applied Biology of the University of Alicante, Dept. of Physiology of the University of Murcia and Institute of Aquaculture of the University of Stirling) and was funded by the Spanish Ministry of Science. Project Reference CTM2009-14362-CO2-01/2.

\section{LITERATURE CITED}

Adey EA, Black KD, Sawyer T, Shimmield TM, Trueman CN (2009) Scale microchemistry as a tool to investigate the origin of wild and farmed Salmo salar. Mar Ecol Prog Ser 390:225-235

> Akyol O, Ertosluk O (2010) Fishing near sea-cage farms along the coast of the Turkish Aegean Sea. J Appl Ichthyol 26:11-15

Arechavala-Lopez P, Sanchez-Jerez P, Bayle-Sempere J, Fernandez-Jover D, Martinez-Rubio L, Lopez-Jimenez JA, Martinez-Lopez FJ (2010a) Direct interaction between wild fish aggregations at fish farms and fisheries activity at fishing grounds: a case study with Boops boops. Aquacult Res 42:1-15

> Arechavala-Lopez P, Uglem I, Sanchez-Jerez P, FernandezJover D, Bayle-Sempere JT, Nilsen R (2010b) Movements of grey mullet Liza aurata and Chelon labrosus associated with coastal fish farms in the western Mediterranean Sea. Aquacult Environ Interact 1:127-136 
Barberá C, Fernandez-Jover D, López-Jiménez JA, González Silvera D, Hinz H, Moranta J (2011) Trophic ecology of the sea urchin Spatangus purpureus elucidated from gonad fatty acids composition analysis. Mar Environ Res 71:235-246

Bjordal A, Skar AB (1992) Tagging of saithe (Pollachius virens L.) at a Norwegian fsh farm: preliminary results on migration. ICES Comm Meet G:35

Brooks S, Tyler CR, Sumpter JP (1997) Egg quality in fish: What makes a good egg? Rev Fish Biol Fish 7:387-416

Brown PB, Hart SD (2010) Soybean oil and other n-6 polyunsaturated fatty acid-rich vegetable oils. In: Turchini GM, Ng WK, Tocher DR (eds) Fish oil replacement and alternative lipid sources in aquaculture feeds. CRC Press, Boca Raton, FL, p 133-160

Bureau DP, Meeker DL (2010) Terrestrial animal fats. In: Turchini GM, Ng WK, Tocher DR (eds) Fish oil replacement and alternative lipid sources in aquaculture feeds. CRC Press, Boca Raton, FL, p 245-266

$>$ Carss DN (1990) Concentrations of wild and escaped fishes immediately adjacent to fish farm cages. Aquaculture 90: $29-40$

Colombo JC, Silverberg N, Gearing JN (1997) Lipid biogeochemistry in the Laurentian Trough. II. Changes in composition of fatty acids, sterols and aliphatic hydrocarbons during early diagenesis. Org Geochem 26:257-274

Cook EJ, Bell MV, Black KD, Kelly MS (2000) Fatty acid compositions of gonadal material and diets of the sea urchin, Psammechinus miliaris: trophic and nutritional implications. J Exp Mar Biol Ecol 255:261-274

Cook PLM, Revill AT, Clementson LA, Volkman JK (2004) Carbon and nitrogen cycling on intertidal mudflats of a temperate Australian estuary. III. Sources of organic matter. Mar Ecol Prog Ser 280:55-72

Dalsgaard J, St. John M, Kattner G, Müller-Navarra D, Hagen W (2003) Fatty acid trophic markers in the pelagic marine environment. Adv Mar Biol 46:225-340

Danielsdottir AK, Marteinsdottir G, Arnason F, Gudjonsson S (1997) Genetic structure of wild and reared Atlantic salmon (Salmo salar L.) populations in Iceland. ICES J Mar Sci 54:986-997

De Silva SS, Francis DS, Tacon AGJ (2010) Fish oils in aquaculture: in retrospect. In: Turchini GM, Ng WK, Tocher DR (eds) Fish oil replacement and alternative lipid sources in aquaculture feeds. CRC Press, Boca Raton, FL, p 1-20

- Dempster T (2004) Biology of fish associated with moored fish aggregation devices (FADs): implications for the development of a FAD fishery in New South Wales, Australia. Fish Res 68:189-201

- Dempster T, Sanchez-Jerez P, Bayle-Sempere JT, GiménezCasalduero F, Valle C (2002) Attraction of wild fish to sea-cage fish farms in the south-western Mediterranean Sea: spatial and short-term temporal variability. Mar Ecol Prog Ser 242:237-252

> Dempster T, Uglem I, Sanchez-Jerez P, Fernandez-Jover D, Bayle-Sempere J, Nilsen R, Bjørn PA (2009) Coastal salmon farms attract large and persistent aggregations of wild fish: an ecosystem effect. Mar Ecol Prog Ser 385: $1-14$

> Dempster T, Sanchez-Jerez P, Fernandez-Jover D, BayleSempere J, Nilsen R, Bjørn PA, Uglem I (2011) Proxy measures suggest coastal fish farms can act as population sources and not ecological traps for wild gadoid fish. PLoS ONE 6:e15646 doi:10.1371/journal.pone.0015646
Deutsch L, Gräslund S, Folke C, Troell M, Huitric M, Kautsky N, Lebel L (2007) Feeding aquaculture growth through globalization: explotation of marine ecosystems for fishmeal. Glob Environ Change 17:238-249

> Dos Santos J, Burkow IC, Jobling M (1993) Patterns of growth and lipid deposition in cod (Gadus morhua L.) fed natural prey and fish-based feeds. Aquaculture 110: 173-189

Falch E, Rustad T, Aursand M (2006) By-products from gadiform species as raw material for production of marine lipids as ingredients in food or feed. Process Biochem 41: 666-674

FAO (Food and Agriculture Organisation) (2009) The state of world fisheries and aquaculture 2008. Available at: ftp://ftp.fao.org/docrep/fao/011/i0250e/i0250e.pdf (accessed on 5 September 2011)

- Felsing M, Glencross B, Telfer T (2005) Preliminary study on the effects of exclusion of wild fauna from aquaculture cages in a shallow marine environment. Aquaculture 243:159-174

Fernandez-Jover D, Lopez-Jimenez JA, Sanchez-Jerez P, Bayle-Sempere J, Gimenez-Casalduero F, MartinezLopez FJ, Dempster T (2007) Changes in body condition and fatty acid composition of wild Mediterranean horse mackerel (Trachurus mediterraneus, Steindachner, 1868) associated with sea cage fish farms. Mar Environ Res 63: $1-18$

> Fernandez-Jover D, Sanchez-Jerez P, Bayle-Sempere J, Valle C, Dempster T (2008) Seasonal patterns and diets of wild fish assemblages associated with Mediterranean coastal fish farms. ICES J Mar Sci 65:1153-1160

Fernandez-Jover D, Sanchez-Jerez P, Bayle-Sempere JT, Arechavala-Lopez P, Martinez-Rubio L, Lopez Jimenez J, Martinez Lopez FJ (2009) Coastal fish farms are settlement sites for juvenile fish. Mar Environ Res 68:89-96

Fernandez-Jover D, Martinez-Rubio L, Sanchez-Jerez P, Bayle-Sempere JT and others (2011) Waste feed from coastal fish farms: a trophic subsidy with compositional side-effects for wild gadoids. Estuar Coast Shelf Sci 91: 559-568

- Fleming IA, Jonsson B, Gross MR (1994) Phenotypic divergence of sea-ranched, farmed, and wild salmon. Can J Fish Aquat Sci 51:2808-2824

Fonteneau A, Pallares P, Pianet R (2000) A worldwide review of purse seine fisheries on FADs. In: Le Gall JY, Cayre P, Taquet M (eds) Pêche thoniére et dispositifs de concentration de poissons. IFREMER, Caraibe-Martinique, p 15-34 (in French with English abstract)

Gao QF, Shin PKS, Lin GH, Chen SP, Cheung SG (2006) Stable isotope and fatty acid evidence for uptake of organic waste by green-lipped mussels Perna viridis in a polyculture fish farm system. Mar Ecol Prog Ser 317:273-283

> Graeve M, Kattner G, Hagen W (1994) Diet-induced changes in the fatty acid composition of Arctic herbivorous copepods: experimental evidence of trophic markers. J Exp Mar Biol Ecol 182:97-110

Grigorakis K, Alexis MN, Taylor KDA, Hole M (2002) Comparison of wild and cultured gilthead sea bream; composition, appearance and seasonal alterations. Int J Food Sci Technol 37:477-484

> Henderson RJ, Forrest DAM, Black KD, Park MT (1997) The lipid composition of sealoch sediments underlying salmon cages. Aquaculture 158:69-83

Hughes AD, Catarino AI, Kelly MS, Barnes DKA, Black KD (2005) Gonad fatty acids and trophic interactions of the 
echinoid Psammechinus miliaris. Mar Ecol Prog Ser 305: 101-111

Iverson SJ (2009) Tracing aquatic food webs using fatty acids: from qualitative indicators to quantitative determination. In: Arts MT, Brett MT, Kainz M (eds) Lipids in aquatic ecosystems. Springer Science + Business Media, New York, NY, p 281-306

> Iverson SJ, Field C, Bowen WD, Blanchard W (2004) Quantitative fatty acid signature analysis: a new method of estimating predator diets. Ecol Monogr 74:211-235

Jacquet J, Hocevar J, Lai S, Majluf P and others (2010) Conserving wild fish in a sea of market-based efforts. Oryx 44:45-56

> Jobling M, Leknes O, Sæther B, Bendiksen E (2008) Lipid and fatty acid dynamics in Atlantic cod, Gadus morhua, tissues: influence of dietary lipid concentrations and feed oil sources. Aquaculture 281:87-94

Kharlamenko VI, Kiyashko SI, Rodkina SA, Imbs AB (2008) Determination of food sources of marine invertebrates from a subtidal sand community using analyses of fatty acids and stable isotopes. Russ J Mar Biol 34:101-109

Kojima S (1956) Fishing for dolphins in the western part of the Japan Sea. 11. Why do the fish take shelter under floating materials? Bull Jpn Soc Fish Oceanogr 40:3-8

Montero D, Izquierdo MS (2010) Welfare and health of fish fed vegetable oils as alternative lipid sources to fish oil. In: Turchini GM, Ng WK, Tocher DR (eds) Fish oil replacement and alternative lipid sources in aquaculture feeds. CRC Press, Boca Raton, FL, p 439-485

Mourente G, Tocher DR (1993) Incorporation and metabolism of ${ }^{14} \mathrm{C}$-labelled polyunsaturated fatty acids in wildcaught juveniles of golden grey mullet, Liza aurata, in vivo. Fish Physiol Biochem 12:119-130

Odutuga AA (1977) Recovery of brain deficiency of essential fatty acids in rats. Biochim Biophys Acta 487:1-9

> Olsen SA, Ervik A, Grahl-Nielsen O (2009) Deep-water shrimp (Pandalus borealis, Krøyer, 1838) as indicator organism for fish-farm waste. J Exp Mar Biol Ecol 381:82-89

Olsen RE, Waagbø R, Melle W, Ringø E, Lall SP (2010) Alternative marine resources. In: Turchini GM, Ng WK, Tocher DR (eds) Fish oil replacement and alternative lipid sources in aquaculture feeds. CRC Press, Boca Raton, FL, p 267-324

Pavlov D, Kjorsvik E, Refsti T, Andersen O (2004) Broodstock and egg production. In: Moksness E, Kjorsvik E, Olsen Y (eds) Culture of cold water marine fish. Blackwell Publishing, Oxford, p 129-203

> Percin F, Sogut O, Altinelataman C, Soylak M (2011) Some trace elements in front and rear dorsal ordinary muscles of wild and farmed bluefin tuna (Thunnus thynnus L. 1758) in the Turkish part of the eastern Mediterranean Sea. Food Chem Toxicol 49:1006-1010

Samuelsen OB, Ervik A, Solheim E (1988) A qualitative and quantitative analysis of the sediment gas and diethylether extract of the sediment from salmon farms. Aquaculture 74:277-285

Sanchez-Jerez P, Dempster T, Fernandez-Jover D, Uglem I and others (2011) Coastal fish farms act as fish aggregation devices (FADs): potential effects on fisheries. In: Bortrone S (ed) Artificial reefs in fisheries management. CRC Press, Boca Raton, FL, p 187-208

Sargent JR, Tocher DR, Bell JG (2002) The lipids. In: Halver JE, Hardy RW (eds) Fish nutrition. Academic Press, San Diego, CA

Scott CL, Falk-Petersen S, Sargent JR, Hop H, Lønne OJ,
Poltermann M (1999) Lipids and trophic interactions of ice fauna and pelagic zooplankton in the marginal ice zone of the Barents Sea. Polar Biol 21:65-70

Serrano R, Blanes MA, Orero L (2007) Stable isotope determination in wild and farmed gilthead sea bream (Sparus aurata) tissues from the western Mediterranean. Chemosphere 69:1075-1080

Skog TE, Hylland K, Torstensen BE, Berntssen MHG (2003) Salmon farming affects the fatty acid composition and taste of wild saithe Pollachius virens L. Aquacult Res 34: 999-1007

Standal IB, Praël A, McEvoy L, Axelson DE, Aursand M (2007) Discrimination of cod liver oil according to wild/farmed and geographical origins by $\mathrm{GC}$ and ${ }^{13} \mathrm{C}$ NMR. J Am Oil Chem Soc 85:105-112

Tacon AGJ, Metian M (2008) Global overview on the use of fish meal and fish oil in industrially compounded aquafeeds: trends and future prospects. Aquaculture 285: $146-158$

> Tocher DR (2003) Metabolism and functions of lipids and fatty acids in teleost fish. Rev Fish Sci 11:107-184

> Tocher DR (2010) Fatty acid requirements in ontogeny of marine and freshwater fish. Aquacult Res 41:717-732

Turchini GM, Torstensen BE, Ng WK (2009) Fish oil replacement in finfish nutrition. Rev Aquacult 1:10-57

Turchini GM, Ng WK, Tocher DR (eds) (2010) Fish oil replacement and alternative lipid sources in aquaculture feeds. CRC Press, Boca Raton, FL

Tuya F, Sanchez-Jerez P, Dempster T, Boyra A Haroun R (2006) Changes in demersal wild fish aggregations beneath a sea-cage fish farm after the cessation of farming. J Fish Biol 69:682-697

- Tzikas Z, Amvrosiadis I, Soultos N, Georgakis Sp (2007) Seasonal variation in the chemical composition and microbiological condition of Mediterranean horse mackerel (Trachurus mediterraneus) muscle from the North Aegean Sea (Greece). Food Contr 18:251-257

> Uglem I, Bjørn PA, Dale T, Kerwath S and others (2008) Movements and spatiotemporal distribution of escaped farmed and local wild Atlantic cod (Gadus morhua L.). Aquacult Res 39:158-170

Uglem I, Dempster T, Bjørn PA, Sanchez-Jerez P, Økland F (2009) High connectivity of salmon farms revealed by aggregation, residence and repeated migrations of wild saithe (Pollachius virens) among farms. Mar Ecol Prog Ser 384:251-260

- Valle C, Bayle-Sempere JT, Dempster T, Sanchez-Jerez P, Giménez-Casalduero F (2007) Temporal variability of wild fish assemblages associated with a sea-cage fish farm in the south-western Mediterranean Sea. Estuar Coast Shelf Sci 72:299-307

Van Der Kraak G, Chang JP, Janz DM (1998) Reproduction. In: Evans DH (ed) The physiology of fishes. CRC Press, Boca Raton, FL, p 465-488

- Vita R, Marín A, Madrid JA, Jiménez-Brinquis B, Cesar A, Marín-Guirao L (2004) Effects of wild fishes on waste exportation from a Mediterranean fish farm. Mar Ecol Prog Ser 277:253-261

Welch A, Hoenig R, Stieglitz J, Benetti D, Tacon A, Sims N, O'Hanlon B (2010) From fishing to sustainable farming of carnivorous marine finfish. Rev Fish Sci 18:235-247

Yildiz M (2008) Mineral composition in fillets of sea bass (Dicentrarchus labrax) and sea bream (Sparus aurata): a comparison of cultured and wild fish. J Appl Ichthyol 24: 589-594 